\title{
Evaluation of position, shape, size and incidence of mental foramen and accessory mental foramen in Indian adult human skulls
}

\author{
Rajani Singh, Ajay Kumar Srivastav \\ Department of Anatomy, CSM Medical University (Former KGMU), Lucknow, UP, India
}

\begin{abstract}
Objectives: Analysis of morphometry and incidences of mental and accessory mental foramina are important for dental surgeons in nerve block and surgical procedures to avoid injury to neurovascular bundle. This study was carried out to present such data on mental and accessory mental foramina in Indian population.

Methods: The study experimented with 100 dried adult human mandibles. Size and position were determined using digital vernier callipers. Incidences and shapes of mental and accessory mental foramina were also observed.

Results: Bilateral mental foramina were presented in all one hundred mandibles. Accessory mental foramina were found in $8 \%$ on left side, $5 \%$ on right side and nil bilaterally. Mental foramina were predominantly rounded. Average diameters of mental and accessory mental foramina were measured as $2.68 \mathrm{~mm}$ and $1.00 \mathrm{~mm}$, respectively. The percentages of locations of mental foramina below the apex of second premolar, between first and second premolars and between second premolar and first molar were found as 68.8, 17.8 and 11.5, respectively. Accessory mental foramina were located $0.67 \mathrm{~mm}$ lateral to mental foramen and below the apex of first molar tooth.

Conclusion: This study may supplement very useful new data of variations in incidence, position, shape and size of mental and accessory mental foramina for Indian population which may help the surgeons, anaesthetists, neurosurgeons and dentists to help carrying out surgical procedures successfully.
\end{abstract}

Key words: accessory mental foramen; mandible; mental foramen; mental nerve; molar; morphometry; premolar

Anatomy 2011;5:23-29, (c) 2011 TSACA

\section{Introduction}

Mental foramen (MF) is located in the body of mandible at an equal distance from the superior and inferior border. Normally, MF is located below the interval between the premolars. It may lie between the apices of lower premolars, below the apex of second premolar. Mental nerve and vessels pass through mental foramen. Identification of mental foramen is important for dental surgeons in nerve block and surgical procedures like apical curettage of mandibular premolars, amalgam filling, peridental surgery etc. to avoid injury to neurovascular bundle. Data from various ethnic groups e.g. Tanzanian, Thai, Chinese, British, Saudi Arabian show the variations in the location of mental foramen. ${ }^{[1]}$
Any foramen in addition to mental foramen is known as accessory mental foramen (AMF) in the body of mandible. Accessory mental foramina tend to exist in the apical area of the first molar and posterior or inferior area of the mental foramen. It is situated below the first molar tooth according to Çağırankaya and Kansu. ${ }^{[2]}$ Ethnic variations in relation to AMF have also been reported. ${ }^{[3]}$ Thus, the knowledge of location, incidence, size, and shape of MF and AMF will facilitate the dental surgeons to apply nerve block in different surgical procedures involving lower jaw. As AMF is due to branching of mental nerve before passing through MF, hence its shape size and verification of its existence will prevent accessory nerve injury during periapical surgery. In addition to this, if this nerve 
is not blocked, paresthesia will be less. There is almost no data available for incidence, shape, size, and position of mental and accessory mental foramina of Indian mandibles. Therefore, the study of which data would be of immense use to dental surgeons in carrying out surgical procedures in Indian population, was performed.

\section{Materials and Methods}

This study was carried out using one hundred dried adult human mandibles of unknown sex in the Department of Anatomy, CSM Medical University Lucknow, UP, India. Mandibles of children and elderly population were discarded. The age group of population whose mandibles were considered for experimentation was between 20-50 years. Digital vernier calliper was used to measure the dimensions of MF and AMF to analyse and examine the size, shape and position of MF and AMF. The incidences of MF and AMF were also observed. The complete data was analysed by using central tendency in measures leading to computation of mean, percentage and range.

\section{Results}

\section{Position of MF in relation to lower teeth}

Mental foramen was situated below the apex of second premolar tooth in $68.8 \%$ of mandibles whereas in $17.8 \%$ of mandibles it was observed between first and second premolars. In $11.5 \%$ it was found between second premolar and first molar and in $2.1 \%$ it was seen below the apex of first premolar.

A typical example of MF is shown in Figure 1 where it is lying between first and second premolar on left side and below the apex of second premolar on right side of mandible.

Mean distances of MF in both sides (left and right) of the mandible from various parameters as landmarks (symphysis menti, posterior border of ramus of mandible, base of mandible and alveolar crest) were computed and recorded in Table 1 specifying the position of MF through numerical measurements:

D1 is the mean distance of mental foramen from posterior border of mandibular ramus both on right and left sides of the mandible, as lying parallel to the body of mandible.

D2 is the mean distance of mental foramen from base of mandible both on right and left sides of the mandible, as lying in the right angle to the base of mandible.

D3 is the mean distance of mental foramen from alveolar crest both on right and left sides of the mandible.

D4 is the mean distance of mental foramen from symphysis menti both on right and left sides of the mandible.

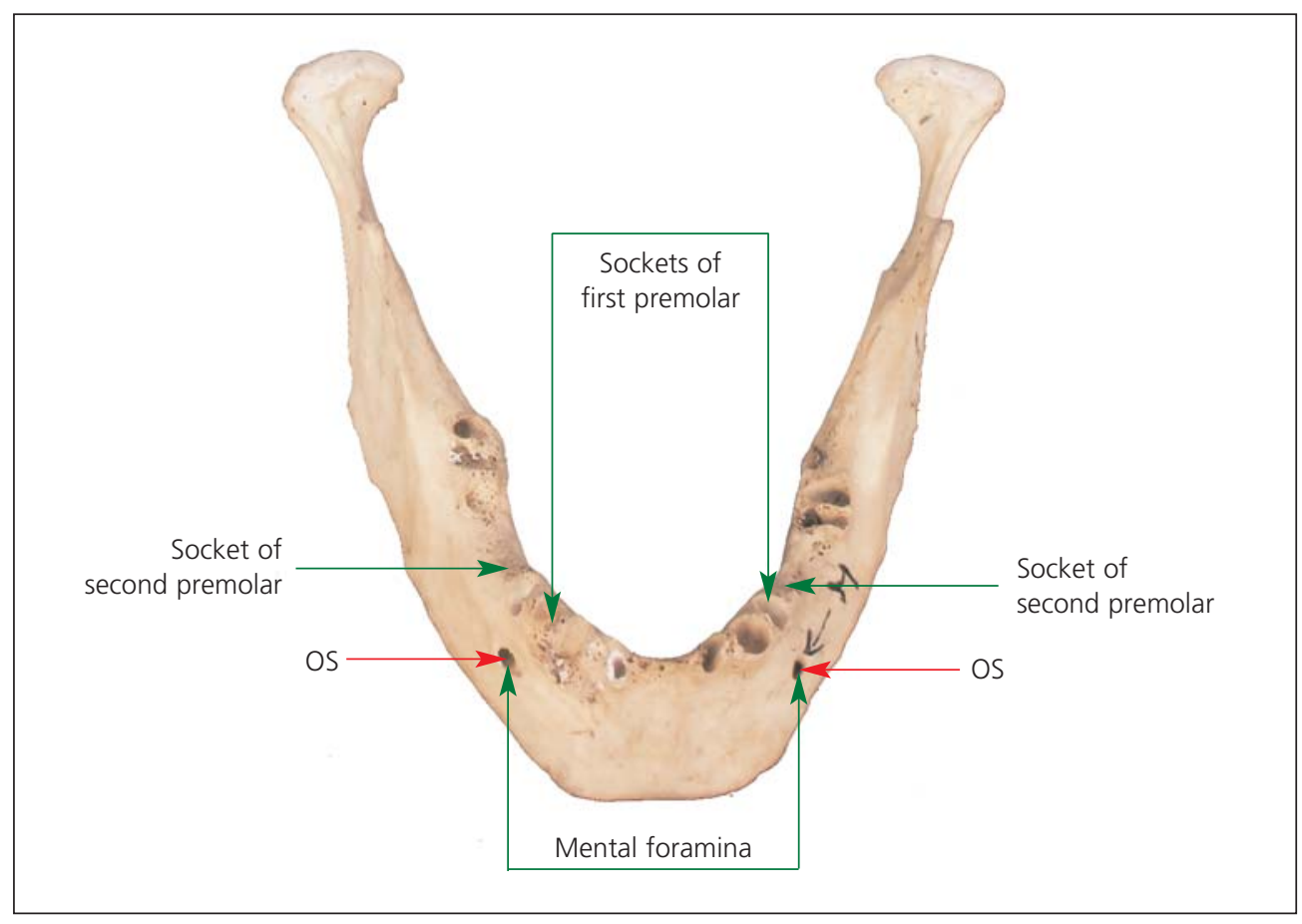

Figure 1. The position and shape of mental foramen in relation to lower teeth. OS: oval shape. 
Table 1

Mean distances of mental foramen from landmarks in both sides (right and left) of mandible

\begin{tabular}{ccccccccc}
\hline \multicolumn{2}{c}{ D1 } & \multicolumn{2}{c}{ D2 } & \multicolumn{2}{c}{ D3 } & \multicolumn{2}{c}{ D4 } \\
\hline \multirow{2}{*}{ Right } & Left & Right & Left & Right & Left & Right & Left \\
\hline \multirow{2}{*}{71.8} & 84.7 & 17.3 & 13.37 & 17 & 18.6 & 29.3 & 30.6 \\
\hline
\end{tabular}

D: distance in mm (for the descriptions of the distances D1, D2, D3 and D4 please see the text).

These distances (D1, D2, D3 and D4) are shown by green arrows and red arrows to various parameters and location of MF in Figure 2.

\section{Position of AMF in relation to lower teeth}

Position of AMF in the body of mandibles in the right side is displayed in Figure 3. It was situated between first and second premolar in 5 out of 100 mandibles in the right side whereas it was observed (Figure 4) below the apex of first molar tooth in 8 out of the same 100 mandibles in the left side (as depicted in Table 2). Average distance between MF and AMF was $0.67 \mathrm{~mm}$ laterally.

\section{Incidence, shape and size}

Incidence, shape and size of MF and AMF are presented in Table 2.

\section{Discussion}

Since, there is almost no data available for incidence, shape, size and position of mental and accessory mental foramina in Indian population to help carrying out surgical procedures around lower jaw, the results of this study can be only compared and discussed with the findings of similar studies performed in different populations from racial point of view.
Figure 2. The position of mental foramen in relation to various parameters (for the descriptions of the distances D1, D2, D3 and D4 please see the text).

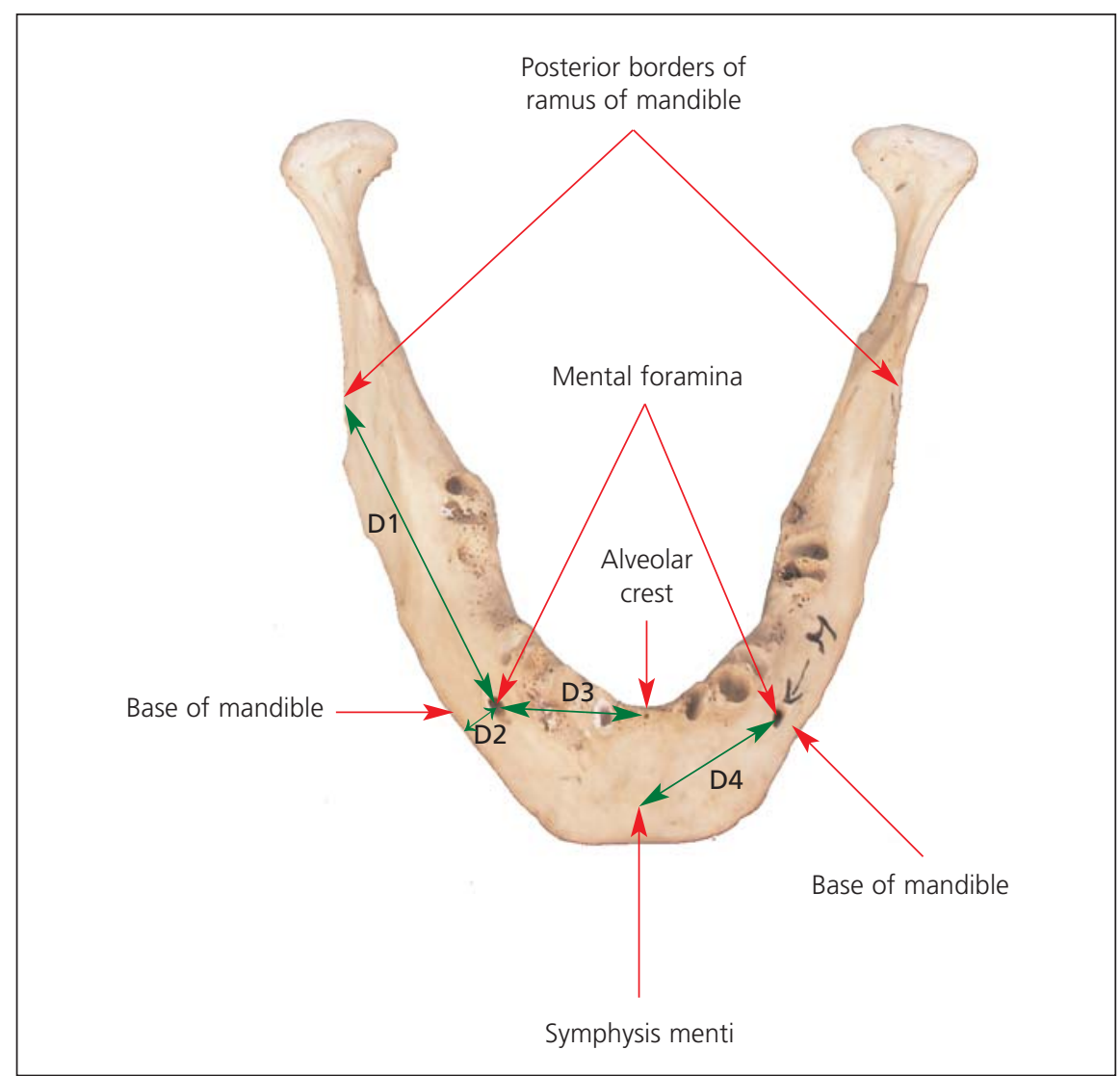


Table 2

Incidence, shape and size of both mental foramen and accessory mental foramen

\begin{tabular}{cccccccccccccc}
\hline Foramina & $\begin{array}{c}\text { Total number } \\
\text { of sides }\end{array}$ & $\begin{array}{c}\text { Incidence } \\
(\%)\end{array}$ & \multicolumn{4}{c}{ Shape } & \multicolumn{4}{c}{ Size } \\
\hline & & & & Round (\%) & Oval (\%) & Range (mm) & Mean (mm) \\
\hline MF & 200 & 100 & 100 & 94 & 87 & 6 & 13 & $1-3$ & $1-6$ & 2.79 & 2.57 \\
AMF & 200 & 5 & 8 & 5 & 8 & Nil & Nil & $0.6-1$ & $0.8-1.5$ & 0.78 & 1.00 \\
\hline
\end{tabular}

MF: mental foramen; AMF: accessory mental foramen.

\section{Position of MF}

Comparison of most common location of MF by various authors for different races is depicted in Table 3.

In the present study, the most common location of MF is below the apex of second premolar tooth in $68.8 \%$ of Indian mandibles. The same position of MF was observed by Wang et al. ${ }^{[4]}$ in Chinese, Santini and Land ${ }^{[5]}$ in Chinese and British, Apinhasmit et al.$^{[6]}$ in Thais, and Phillips et al. ${ }^{[7]}$ as detailed in the Table 3. Its frequency in our study is higher than the others. According to Olasoji et al. ${ }^{\left[{ }^{[8}\right.}$ in North Nigerians and Aktekin et al. ${ }^{[9]}$ the most common location of MF is between first and second premolars. In our study, this position was found in $17.8 \%$ of Indian mandibles.
Mean distances between the MF and various parameters (symphysis menti, posterior border of ramus of mandible, base of mandible, alveolar crest) have been compared in Table 4, are comparable to that observed by Wang et $\mathrm{al}^{\left[{ }^{[4]}\right.}$ and Souaga et al. ${ }^{[10]}$ The findings of Yeşilyurt et al. ${ }^{[11]}$ regarding aforementioned mean distances of MF are much lower than the current study.

\section{Position of AMF}

AMF below the first molar was observed under current study similar to Çağırankaya and Kansu. ${ }^{[2]}$ Much literature is not available on the position of AMF in relation to teeth position. According to Toh et al. ${ }^{[12]}$, distance between the MF and AMF in three cadavers are 0.67

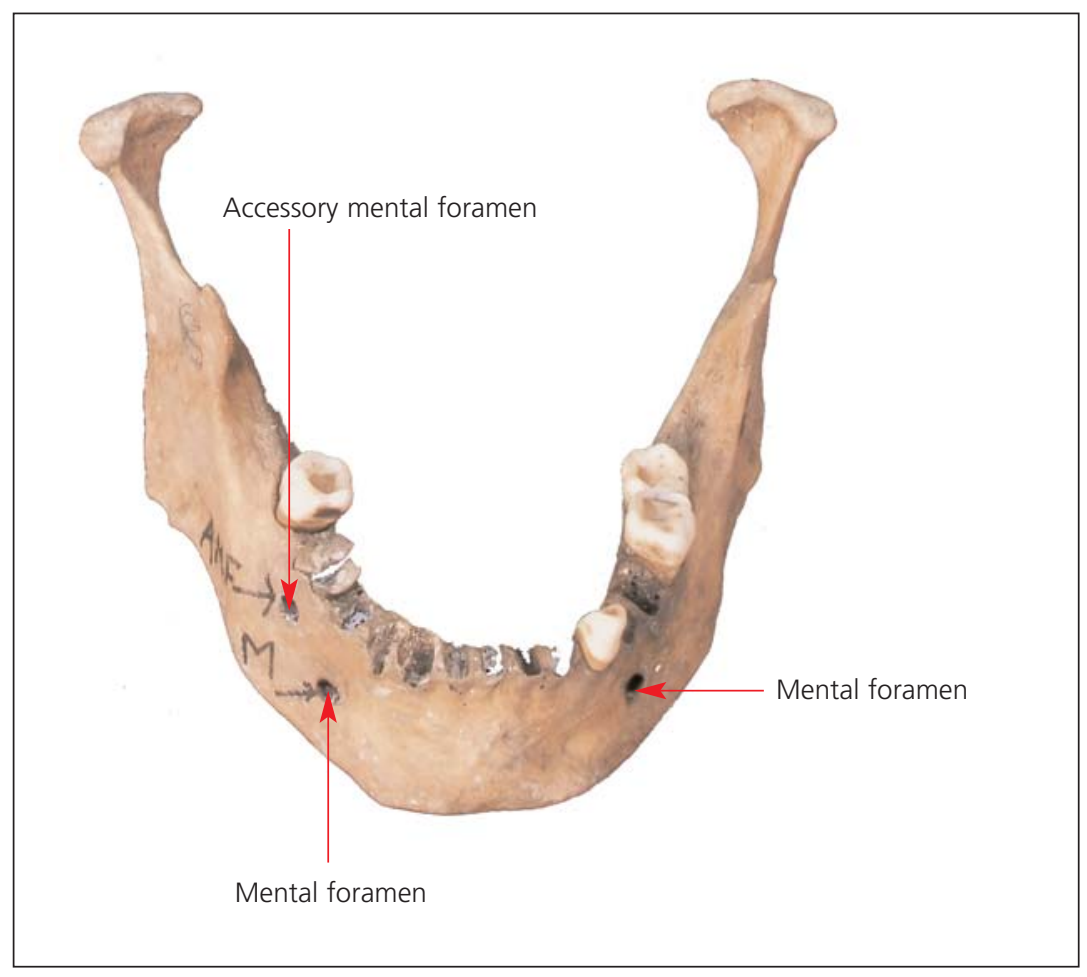

Figure 3. The position of accessory mental foramen in right side. 
Table 3

Comparison of most common location of mental foramen by various authors

\begin{tabular}{|c|c|c|c|c|}
\hline Authors (year) & Location of MF & $\%$ of $\mathrm{MCL}$ & Race & D4:D1 \\
\hline Present study & Below the apex of IInd premolar & 68.8 & Indian & $1: 3.2$ \\
\hline Wang et al. ${ }^{4}$ (1986) & Below the apex of IInd premolar & 58.98 & Chinese & $1: 2.6$ \\
\hline Santini \& Land 5 (1990) & Below IInd premolar & 52.9 & Chinese & ----- \\
\hline Santini \& Land 5 (1990) & Between apices of Ist \& IInd premolar & 65 & British & $1: 2.7$ \\
\hline Apinhasmit et al. ${ }^{6}$ (2006) & Below IInd premolar & ----- & Thais & ----- \\
\hline Phillips et al. ${ }^{7}$ (1992) & Inferior to crown of IInd premolar & ----- & NA & ----- \\
\hline Olasoji et al. ${ }^{8}$ (2004) & Between of Ist \& IInd premolar & ----- & $\begin{array}{l}\text { North } \\
\text { Nigerian }\end{array}$ & ----- \\
\hline
\end{tabular}

MF: mental foramen; MCL: most common location of MF; NA: not available; D4:D1: the ratio of the mean distance of MF from symphysis menti (D4) and mean distance of MF from posterior border of ramus of mandible (D1).

$\mathrm{mm}, 2.1 \mathrm{~mm}$ and $5.74 \mathrm{~mm}$ whereas the authors in present study observed mean distance of AMF from MF to be $0.67 \mathrm{~mm}$ which is matching with the distance observed by Toh et al. ${ }^{[12]}$ in one of the three cadavers. The findings of distances in remaining two cadavers by same authors are beyond the range $(0.6-1.5 \mathrm{~mm})$ of these distances of AMF from MF under the present study which provides precise location of AMF in relation to MF in Indian population. This data may save nerve block failure in surgical procedures around AMF.

\section{Shape of MF}

In the present study, predominant shape observed is round both on right (94\%) and left sides (87\%) which is similar to study conducted by Al-Khateeb et al. ${ }^{[13]}$ However Oliveira Junior et al. ${ }^{[14]}$ reported round shape only in $26.2 \%$ and $28.7 \%$ of mandibles on right and left sides respectively and in rest of mandibles, oval shape was observed $73.8 \%$ on right side and $71.3 \%$ on left side.

\section{Size of MF}

The present observations bring out average horizontal dimension of MF to be $2.8 \mathrm{~mm}$ on right side and 2.57 $\mathrm{mm}$ on the left side which are close to study by Oğuz and Bozkır ${ }^{[15]}$ over 34 dry mandibles of Turkish population with $2.93 \mathrm{~mm}$ horizontal dimension on right side and $3.14 \mathrm{~mm}$ on left side.

\section{Size of AMF}

In the present study, the average dimension of AMF is 1 $\mathrm{mm}$. There is no available data to compare the size of $\mathrm{AMF}$ in the published literature.

Figure 4. The position of accessory mental foramen in left side.

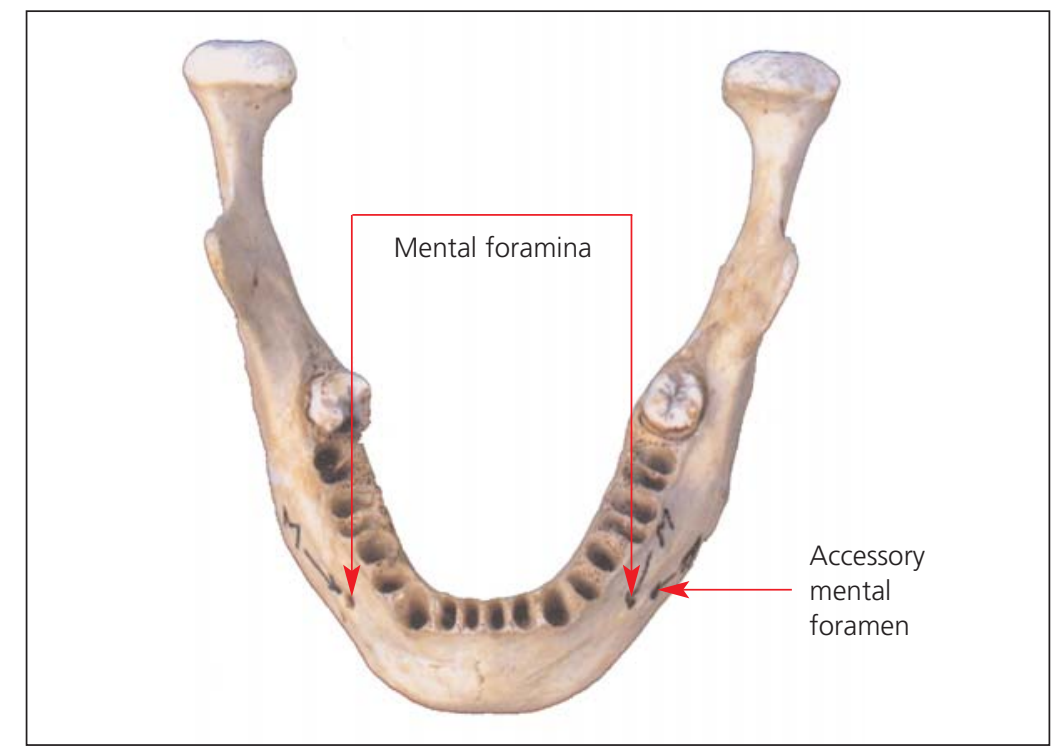


Table 4

Comparison of mean distances of MF mental foramen from various parameters (landmarks)

\begin{tabular}{|c|c|c|c|c|c|c|c|c|}
\hline \multirow[b]{2}{*}{ Authors (year) } & \multicolumn{2}{|c|}{ D1 } & \multicolumn{2}{|c|}{ D2 } & \multicolumn{2}{|c|}{ D3 } & \multicolumn{2}{|c|}{ D4 } \\
\hline & Right & Left & Right & Left & Right & Left & Right & Left \\
\hline Present study & 71.8 & 84.7 & 17.3 & 13.37 & 17 & 18.6 & 29.3 & 30.6 \\
\hline Yeşilyurt et al. ${ }^{10}$ (2008) & 48.58 & 48.27 & NA & NA & NA & NA & 19.18 & 19.37 \\
\hline Souaga et al. ${ }^{11}$ (2004) & NA & NA & \multicolumn{2}{|c|}{$\begin{array}{c}14.89(\mathrm{M}) \\
14.21(\mathrm{~F})\end{array}$} & \multicolumn{2}{|c|}{$\begin{array}{c}16.16(\mathrm{M}) \\
15.66(\mathrm{~F})\end{array}$} & NA & NA \\
\hline Wang et al. ${ }^{4}(1986)$ & \multicolumn{2}{|r|}{74.14} & \multicolumn{2}{|c|}{14.70} & \multicolumn{2}{|c|}{ NA } & \multicolumn{2}{|c|}{28.06} \\
\hline
\end{tabular}

D: distance in mm (for the descriptions of the distances D1, D2, D3 and D4 please see the text); NA: not available; F: female; M: male

\section{Incidences of MF}

MF is present in all 100 mandibles (100\%) and bilateral like the findings of Oliveira Junior et al. ${ }^{[14]}$ in 80 mandibles. However de Frietas et al. ${ }^{[16]}$ reported $0.4 \%$ absence of MF.

\section{Incidences of AMF}

In the present study AMF is present in 13 mandibles in one side only. Eight percent of total 100 mandibles are found on left side and $5 \%$ on right side. The incidence in American whites (1.8\%) as reported by Sawyer et al..$^{[3]}$ is much lower than the current study $(13 \%)$ and close to the findings of Riesenfeld ${ }^{[17]}(12.5 \%)$ in Polinesians. Oliveira Junior et al. ${ }^{[14]}$ reported 5\% AMF in total mandibles studied by him which is also lower than in present study. The incidence of AMF in present study is higher than that observed by Gershenson et al. ${ }^{[18]}(2.8 \%)$ in Israeli.

\section{Conclusion}

The incidence of MF is $100 \%$. But AMF is observed in only $13 \%$ of mandibles. Therefore verification of existence of AMF is very important for surgeons because ignorance of presence of AMF may lead to nerve block failure or insufficient anaesthesia.

The most common position of MF is below the apex of second premolar, second most common position is between first and second premolars followed by third most common position between the second premolar and first molar. But very rarely MF was found below the apex of first premolar in Indian population. This along with mean distances with respect to various landmarks may help the surgeons to locate the MF.

We think that this study may supplement very useful new data of MF and AMF for Indian population which may help the surgeons, anaesthetists, neurosurgeons and dentists to help carrying out surgical procedures successfully.

\section{References}

1. Green RM. The position of mental foramen: a comparison between southern Chinese and other ethnic and racial groups. Oral Surg. Oral Med Oral Pathol 1987;63:287-90.

2. Çağırankaya LB, Kansu H. An accessory mental foramen: a case report. J Contemp Dent Pract 2008;9:1-5.

3. Sawyer DR, Kiely ML, Pyle MA. The frequency of accessory mental foramina in four ethnic groups. Arch Oral Biol 1998;43:417-20.

4. Wang TM, Shih C, Liu, JC, Kook J. A clinical and anatomical study of the location of the mental foramen in adult Chinese mandibles. Acta Anat (Basel) 1986;126:29-33.

5. Santini A, Land M. A comparison of the position of mental foramen in Chinese and British mandibles. Acta Anat (Basel) 1990;137:208-12.

6. Apinhasmit W, Methathrathip D, Chompoopong S, Sangvichien S. Mental foramen in Thais: an anatomical variation related to gender and side. Surg Radiol Anat 2006;28:529-33.

7. Phillips JL, Weller RN, Kulid JC. The mental foramen: size, orientation and positional relationship to the mandibular second premolar. J Endod 1992;18:271-4.

8. Olasoji HO, Tahir A, Ekanem AU, Abubakar AA. Radiographic and anatomic locations of mental foramen in northern Nigerian adults. Niger Postgrad Med J 2004;11:230-3.

9. Aktekin M, Çelik HM, Çelik HH, Aldur MM, Akşit MD. Studies on the location of mental foramen in Turkish mandibles. Morphologie 2003;87:17-9.

10. Souaga K, Adon A, Angoh Y. Topographical and morphological study of the mandibular foramen in black Africans from Ivory Coast. Odontostomatol Trop 2004;27:17-21. [Article in French]

11. Yeşilyurt H, Aydınlıŏglu A, Kavaklı A, et al. Local differences in the position of the mental foramen. Folia Morphol (Warsz) 2008;67:32-5.

12. Toh H, Kodama J, Yanagisako M, Ohmori T. Anatomical study of accessory mental foramen and distribution of its nerve. Okajimas Folia Anat Jpn 1992;69:85-7. 
13. Al-Khateeb T, Al-Hadi Hamasha A, Ababneh KT. Position of mental foramen in northern regional Jordanian population. Surg Radiol Anat 2007;29:231-7.

14. Oliveira Junior EM, Araiyo ALD, Da Silva CMF, SousaRodrigues CF, Lima FJC. Morphological and morphometric study of mental foramen on the M-CP-18 Jiachenjiang point. International Journal of Morphology (Temuco) 2009;27:231-8.

15. Oğuz Ö, Bozkır MG. Evaluation of location of mandibular and mental foramina in dry young adult human males, dentulous mandibles. West Indian Med J 2002;51:14-20.
16. de Fritas V, Madeira MC, Toledo Filho JL, Chagas CF. Absence of mental foramen in dry human mandibles. Acta Anat (Basel) 1979;104:353-5.

17. Riesenfeld A. Multiple infraorbital, ethmoidal and mental foramina in the races of man. Am J Phys Anthropol 1956;14:85-100.

18. Gershenson A, Nathan H, Luchansky E. Mental foramen and mental nerve: changes with age. Acta Anat (Basel) 1986;126:21-8.

Correspondence to: Dr. Rajani Singh

Department of Anatomy, CSM Medical University, Lucknow, 226001 UP, India

Phone: 052222576 71; Fax: 05222257539

e-mail: nani_sahayal@rediffmail.com

Conflict of interest statement: No conflicts declared. 